\title{
Thermo-Mechanical Post Buckling Analysis of Multiwall Carbon Nanotube-Reinforced Composite Laminated Beam under Elastic Foundation
}

https://doi.org/10.1515/cls-2019-0018

Received Jun 20, 2019; accepted Aug 16, 2019

\begin{abstract}
In present paper, buckling analysis is performed over laminated composite beam incorporating multi walled carbon nanotube (MWCNT) polymer matrix and then reinforced with E-glass fiber in an orthotropic manner under inplane varying thermal and mechanical loads by finite element method (FEM). Aim of the study is to develop a model which accurately perform the buckling deterministic analysis of multi-walled carbon nanotube reinforced composite laminated beam (MWCNTRCLB) with the evaluation of material property by applying HalpinTsai model. Combined Higher order shear deformation theory and Pasternak elastic foundation based on von Karman nonlinear kinematics and Winkler cubic nonlinearity respectively, are successfully implemented. Through minimum potential energy principle, generalized static analysis is performed using FEM, based on interactive MATLAB coding. The critical buckling load and critical buckling temperature is presented under the action of inplane variable mechanical and thermal load, with different boundary conditions, beam thickness ratio and MWCNT aspect ratio, variation with MWCNT volume fraction and coefficient of thermal expansion, with and without foundation for linear and nonlinear cases.
\end{abstract}

Keywords: Single and Multi walled carbon nanotube; laminated composite beam; FEM; HSDT; thermal buckling

\section{Introduction}

This paper focused to present analytical study of the composite material incorporated with multi walled car-

\footnotetext{
*Corresponding Author: Achchhe Lal: Mechanical engineering department, SVNIT, Surat, Gujarat, India. (395007); Email: achchhelal@med.svnit.ac.in, lalachchhe@yahoo.co.in Kanif Markad: Mechanical engineering department, SVNIT, Surat, Gujarat, India. (395007); Email: kmarkad13@gmail.com
}

bon nanotube (MWCNT) and E-glass reinforced, for better structural, aviation, naval, civil infrastructure and many more applications. Though the numerous study has been done over the laminated composite material, the buckling in the structures is one of the often cause of the failure [13]. So it becomes essential to study and analyze the mechanism of the buckling in the laminated composite beam and try to improve the strength against the buckling. However, to predict the accurate response of the material characteristics is one of the challenging problem. This leads to study of the buckling behaviour of fiber reinforced polymer composite and then improve the performance by addition of the carbon nanotube (CNT) in the laminated composite beam.

The researchers showed that the addition of CNT's in the polymer matrices can lead to significant improvement in the composite properties even at very low volume fractions of CNTs. Chavan and Lal [4], Huang et al. [5], Vo-duy et al. [6] effectively evaluated elastic properties of the uniformly dispersed functionally graded CNT reinforced composites by Mori Tanaka method or extended rule of mixture. Gunay [7] examined the stress transfer behaviour in single walled carbon nanotube reinforced composites. The modelling of three layers of interface, matrix and CNT done together. Lal and Markad [8], Arani and Zamani [9] examined the performance of carbon nanotube reinforced laminated composite material. The Mori Tanaka, rule of mixture and Halpin TSai approach successfully implemented in paper for evaluation of material properties influenced by aggregation of CNTs and UD-CNT. Similarly Thakur et al. [10] utilized the Halpin TSai model to find the elastic properties of nano clay platelets with CNTRC system. Yip et al. [11] reported the fabrication of graphite reinforced polymer laminated composite (GRPC) for checking the shear and bending strength of CNT reinforced composites with different volume fractions. The work was extended by Islam et al. [12] showing the effect of modification of matrix material. Zaeri et al. [13] added nanoclay and MWCNT into matrix and performed dynamic mechanical analysis, low impact test and bending test. Coordinates of CNT and interrelation between 2, 3, 4 atoms were represented with

¿ Open Access. ( 2019 A. Lal and K. Markad, published by De Gruyter. (Cc) BY 4.0 License 
the help of several codes. Cantournet [14] investigated the mechanical behaviour of elastomeric material as carbon nanotubes. Stress-strain behaviour of elastomers under tension and compression were presented and also explained nature of material behaviour with incorporation of MWCNT in different volume fractions.

Buckling is the sudden sideway deflection occurred in beam, plate, shell whenever axially loaded the member. The beam or panels are generally equilibrium state under low inplane compressive loads, but they will go under nonequilibrium state whenever magnitude of load is get increased. So, it can say that stage occurs where fiat beam configuration is no more remains and sudden sideway deflection observed Bipin et al. [15]. Kumar and Srinivas [16, 17], Thomas and Suresh [18], Fan [19] were investigated the buckling analysis of functionally graded (FG) CNT beam, and also the material property of the composites were found either by Mori Tanaka or rule of mixture method. Many of them also analyzed the effect of beam aspect ratio, volume fraction of CNT (Vcnt) over buckling response of the beam. Yas et al. [20] used the rule of mixture for calculation of material property of composite CNTRC beam. Using generalized differential quadrature method (GDQM) with Hamilton's principle the equations were formulated for the analysis. Their study also revealed the effect of foundation, Vcnt, beam slenderness ratio with boundary condition. Vodenitcharova et al. [21] examined the effect of local buckling over SWCNTR beam and reported that, thick matrix SWCNT layer buckles locally at minimum bending angle with large flattening ratios. Madhu et al. [22] dealed with the buckling analysis of CNTR polymer composite plate with Mori Tanaka method for elastic material property evaluation. Using classical laminate theory (CLT) buckling behaviour examined with varying plate aspect ratio. Kahya et al. [23] analyzed the composite laminated beam (CLB) by FEM for predicting the buckling response using first order shear deformation (FSDT) theory under different boundary conditions and laminate stacking sequence. Atlihan [24] investigated the buckling response of the laminated composite beam by application of unit compressive load over free end of the beam. Also effect of ply orientation, boundary condition and stacking sequence were observed through numerical study. Kim et al. [25], Lim and Parsons [26] used the finite element (FE) formulation for composite beam and shell element to find the buckling and post buckling response with langrage multiplier enforcing boundary conditions and kinematic constraints. Narendar [27] used the isotropic graphane sheet for the nonlocal small effect of buckling analysis using variable refined plate theory. Pradhan [28] used HSDT approach with Eringen to predict the buckling behaviour of isotropic one layer graphene sheet and obtained solution for critical buckling load (CBL). Chaudhari et al. [29] performed the thermo-mechanical post buckling analysis utilizing the HSDT with von Karman nonlinearity. Rafiee et al. [30] studied response of epoxy/graphene nanocomposite beam experimentally and observed that with small percentage of addition of graphene platelets in matrix improves the performance beam in terms of CBL. Khdeir and Reddy [31] studied the rectangular beam for buckling analysis with refined beam theory under different boundary conditions. Also relation between classical and shear deformation theory were established. Karamanli and Aydogdu [32] performed the buckling analysis of CLB with the inplane variable load with different boundary conditions and beam aspect ratio.

There are many unobvious situations may arise during working where extensive temperature change may get occurred. For example, fire in case of civil structural and ship panel's case, rockets and spaceships earth reentry. Similar to mechanical buckling, instability in the structures may get arise if thermal stress distribution inherently increases. Or if beam is clamped from both the ends, and heated then thermal compressive stresses are setup into the beam. If this value reaches to critical level, then buckling will get produce and this is termed as critical buckling temperature (CBT). Bouazza et al. [33] and Aydogdu [34] analyzed the CLB subjected to uniform distribution of temperature along the thickness under simply support condition or sets of boundary conditions. Shen and Xiang [35] and Yaghoobi et al. [36] focused on thermal post buckling analysis of FG-CNTRC and FG beam in thermal environment respectively. Functionally graded and uniformly distributed reinforcement types of beam were considered. Yaghoobi et al. also utilized the nonlinear elastic foundation under thermo-mechanical loading. Similarly Li and Batra [37] and Li and Qiao [38] utilized the nonlinear/linear foundation for the buckling analysis of Euler's Bernoulli beam and anisotropic beam respectively. Li and Song [39] performed the large thermal deflection analysis of Timoshenko beam experiencing nonuniform temperature rise. Pesic et al. [40] predicted the thermo-mechanical loading response on 3D framed thin walled open cross section. The properties were utilized are the temperature dependent so that when temperature increased the material property will reduced down. Yazdani et al. [41] used the CLB with piezoelectric layer for the buckling analysis subjected to uniform voltage and temperature, under various boundary conditions. Liu et al. [42] checked the response of composite column for the non-uniform distribution of temperature and compressive loading. When heat flux is experienced by the one end of structure. Lee and Choi [43] in- 
vestigated the ability of the shape recovery force with thermal buckling and post buckling of shape memory alloy (SMA) beam. Fu et al. [44] and Akbas [45] performed the thermal buckling and post buckling analysis of CLB under uniform rise in temperature and different boundary conditions. Kocatürk and Akbas [46, 47] analyzed the Timoshenko FG beam with full non-linearity by lagrangian approximation subjected to thermal loading. Post buckling analysis of considered FG beam were performed with considering the material properties to be temperature dependent.

Available study shows that, in case buckling analysis of beam/panel member, the uniform axial load or uniform thermal load has been considered. With the case of thermal buckling, the buckling has been considered to be occurred because of increased temperature of the member or applying thermal atmosphere. But as stated by Hurang et al. [48], variation in the axial load study have very wide range of scope in practical point of view. In case of space shuttle, whenever it re-enters into earth orbit, it has to be bear variable axial thermal load. Also, there are certain structures who experienced the variable mechanical load at different axial position during their working conditions. By considering all this facts, it is become essential to perform the buckling analysis of structural member like beam who considers the variable inplane axial mechanical load (VIAML) as well as variable inplane axial thermal load (VIATL). One more observation comes out from the available literature, is that, the buckling performance of the beam/ plate tried to increase by addition of SWCNT or MWCNT or nanoclay, reinforcing with either FG or fiber. But no one has performed the critical buckling analysis considering matrix and MWCNT, matrix and SWCNT as a new matrix which reinforced into fiber, and observing the effect of variation of CNT parameters under different boundary conditions, along with foundation effect.

In the present study, multi walled carbon nanotube reinforced composite laminated beam (MWCNTRCLB) is used for the linear and nonlinear critical buckling analysis using HSDT and von Karman nonlinearity. The effect of SWCNT, MWCNT with varying aspect ratio and CNT volume fraction studied for critical buckling analysis. The MWCNTRCLB is subjected to axially varying inplane mechanical and thermal loading along the length. In addition, the buckling performance of the composite beam is analyzed for different beam aspect ratio, boundary conditions, stacking sequence and orientations, ratio of coefficient of thermal expansion with and without PasternakWinkler foundation parameters.

\section{General mathematical formulation}

\subsection{Geometry of the CLB}

The behaviour of the SWCNTRCB and MWCNTRCSB is discussed and shown with the utilization of HSDT model under Pasternak elastic foundation under the action of the uniaxial varying mechanical and thermal loading in Figure 1.

Figure 1 shows the MWCNTRCLB with length of the ' $a$ ', width of the ' $b$ ' and thickness ' $h$ ' along $\mathrm{X}$, $\mathrm{Y}$ and $\mathrm{Z}$ direction respectively. The beam is experiencing the (VIAML- $N_{n}^{m_{x}}$ ) as well as (VIATL- $N_{n}^{T_{x}}$ ) at its end. The graphical view of VIAML/VIATL is shown in the Figure 2. It is assumed that beam is supported with elastic foundation excluding any separation between beam and supporting foundation.

The interaction between supporting foundation and MWCNTRCLB can be presented as, Lal et al. [4, 8]

$$
p=w\left(K_{1}+w^{2} K_{3}\right)-\left(\partial^{2} w / \partial x^{2}\right) K_{2}
$$

The above expression $p$ is the reaction force exerted by spring on the beam and $w$ is the displacement of the CLB along $Z$ direction. The parameters $K_{1}, K_{2}, K_{3}$ are the linear normal spring, Pasternak (shear) and nonlinear normal spring stiffness parameters of foundation system, respectively.

\subsection{Elastic material property calculation of MWCNTRC}

MWCNT and matrix is added together to form new matrix, which is further reinforced with fiber. The elastic material property of this three phase composite is evaluated by applying Halpin Tsai approach. Eq. (2) shows the elastic modulus of combined CNT and matrix, termed as new matrix, which can be expressed as, Kumar and Srinivas [16, 17], Lal et al. $[4,8]$

$$
\begin{aligned}
E_{m} & =\left(\frac{3}{8}\right)\left[\frac{1+\xi_{L}\left\{\frac{\left(E_{m w} / E_{m}\right)-1}{\left(E_{m w} / E_{m}\right)+2(L / t)}\right\} V_{m w}}{1-\left\{\frac{\left(E_{m w} / E_{m}\right)-1}{\left(E_{m w} / E_{m}\right)+2(L / t)}\right\} V_{m w}}\right] E_{m} \\
& +\left(\frac{5}{8}\right)\left[\frac{1+\xi_{T}\left\{\frac{\left(E_{m w} / E_{m}\right)-1}{\left(E_{m w} / E_{m}\right)+2}\right\} V_{m w}}{1-\left\{\frac{\left(E_{m w} / E_{m}\right)-1}{\left(E_{m w} / E_{m}\right)+2}\right\} V_{m w}}\right] E_{m}
\end{aligned}
$$

Where $E_{m}$ and $L=a$ are the elastic modulus of epoxy and length of MWCNTs. $t$ is the thickness of MWCNT which can be evaluated as,

$$
t=\left(\frac{D_{o}-D_{i}}{2}\right)=\left(\frac{\left[D_{s o}+2\left(N_{w}-1\right) h_{i n}\right]-D_{s i}}{2}\right) ;
$$



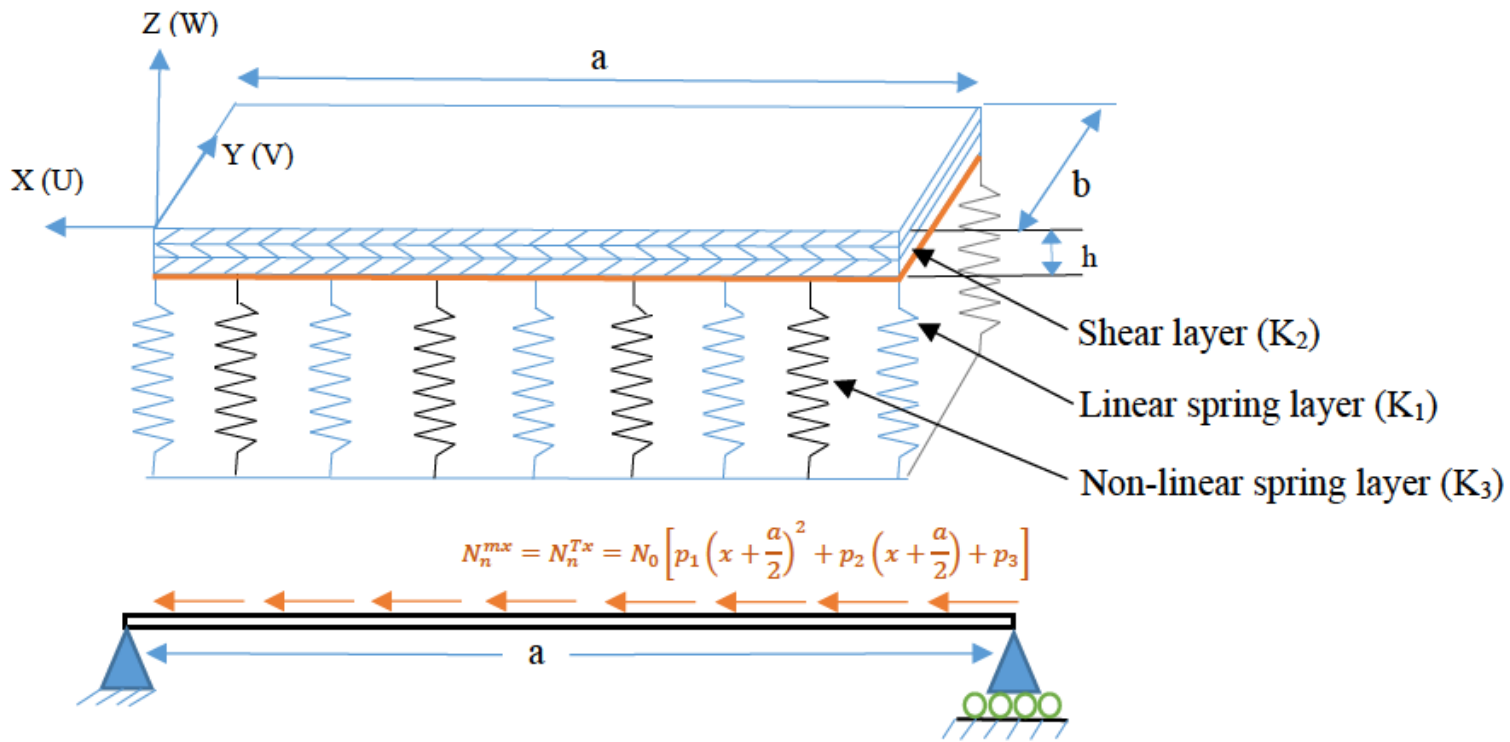

Figure 1: Geometrical configuration of MWCNTRCLB under variable polynomial inplane loading
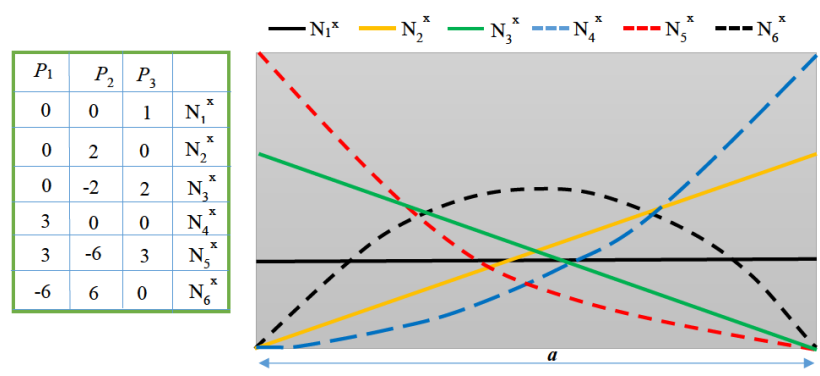

Figure 2: Variation of axially variable inplane buckling load through the beam length [32]

$$
\begin{aligned}
D_{s o} & =D_{c n t}+t_{c n t} ; \quad D_{s i}=D_{c n t}-t_{c n t} ; \\
D_{c n t} & =\frac{\sqrt{3\left(m^{2}+n^{2}+n m\right)}}{\pi} a_{c-c}
\end{aligned}
$$

In Eq. (3), $m$ and $n$ indicates the chiral vector of nanotube, $\mathrm{t}_{c n t}$ is the CNT wall thickness and $a_{c c}$ shows the carbon bond length.

Effective modulus of elasticity of MWCNT can be written as,

$$
E_{m w}=\left(t_{c n t} N_{w} Y_{i}^{c n t}\right) /\left(\left(N_{w}-1\right) h_{\text {in }}+t_{c n t}\right)
$$

Where, $\mathrm{N}_{w}$ shows number of walls used in CNTs. $h_{\text {in }}$ is the inner wall spacing, $Y_{i}^{\text {cnt }}$ elastic property in terms of shear moduli, elastic modulii, poissons ratio and density of SWCNT.

Further using micromechanical approach, the longitudinal, transverse and shear modulus of composite can be expressed as, Bhardwaj et al. [52],

$$
E_{1}=\left(E_{f} V_{f}\right)+\left(E_{m} V_{m}\right)
$$

$$
\begin{aligned}
& E_{2}=\left[\frac{1+\xi_{T} \frac{\left(E_{f} / E_{m}\right)-1}{\left(E_{f} / E_{m}\right)+2} V_{C N T}}{1-\frac{\left(E_{f} / E_{m}\right)-1}{\left(E_{f} / E_{m}\right)+2} V_{C N T}}\right] E_{M} \\
& G_{12}=\left[\frac{1+\xi_{T} \frac{\left(G_{f} / G_{m}\right)-1}{\left(G_{f} / G_{m}\right)+1} V_{C N T}}{1-\frac{\left(G_{f} / G_{m}\right)-1}{\left(G_{f} / G_{m}\right)+1} V_{C N T}}\right] G_{m}
\end{aligned}
$$

The Poisson's ratio of the composite material can be shown by,

$$
v_{12}=v_{f} V_{f}+v_{m} V_{m}
$$

Coefficient of thermal expansion (CTE) along X and Y direction by Shapery model can be expressed as, Lal et al. [8]

$$
\begin{aligned}
& \alpha_{1}=\frac{V_{c n t} E_{1}^{c n t} \alpha_{1}^{c n t}+V_{m} E^{m} \alpha^{m}}{V_{c n t} E_{1}^{c n t}+V_{m} E^{m}} \text { and } \\
& \alpha_{2}=\left(1+v_{12}^{c n t}\right) V_{c n t} \alpha_{2}^{c n t}+\left(1+v^{m}\right) V_{m} \alpha^{m}-v_{12} \alpha_{1}
\end{aligned}
$$

\subsection{Displacement field equation}

Displacement field equation for an arbitrary MWCNTRCB along $\mathrm{X}$ and $\mathrm{Z}$ direction based on HSDT utilizing $\mathrm{C}^{\circ}$ continuity for computational simplicity can be represented as, Reddy [50, 51]

$$
\begin{aligned}
\bar{u}(x, z) & =u+\left(c_{1} z-c_{2} z^{3}\right) \psi_{x}-c_{2} z^{3} \phi_{x} \text { and } \\
\bar{w}(x, z) & =w \text { with } c_{1}=1, c_{2}=4 / 3 h^{2}
\end{aligned}
$$

In this expression mid-plane axial, transverse displacement, rotation of normal to the mid-plane along $y$ - axis and 
slope along $\mathrm{x}$ - axis represented as $\mathrm{u}, \mathrm{w}, \psi_{x}$ and $\phi=\partial w / \partial x$ respectively.

A $\mathrm{C}^{\circ}$ continuous isoparametric $\mathrm{FE}$ approach with four degrees of freedom (DOFs) per node is proposed for present formulation, and can be written as

$$
\{q\}=\left[\begin{array}{llll}
u & w & \phi_{x} & \psi_{x}
\end{array}\right]^{T}
$$

\subsection{Stress-strain relationship}

The total strain vector can be written as,

$$
\{\bar{\varepsilon}\}=\left\{\bar{\varepsilon}^{L}\right\}+\left\{\bar{\varepsilon}^{N L}\right\}-\left\{\bar{\varepsilon}^{T}\right\}
$$

The Eq. (10a) can be further written as $[4,8]$

$$
\{\bar{\varepsilon}\}=[B]\{q\}+\frac{1}{2}\left|\frac{1}{2}\left[\frac{\partial w}{\partial x}\right]^{T}\right|\left\{\frac{\partial w}{\partial x}\right\}-\{\alpha\} \Delta T
$$

Where $\left\{\bar{\varepsilon}_{L}\right\},\left\{\bar{\varepsilon}^{N L}\right\}$ and $\left\{\bar{\varepsilon}^{T}\right\}$ are the linear, non-linear and thermal strain vectors, $[\mathrm{B}]$ and $\{q\}$ are the strain displacement matrix and displacement field vector, $\left\{\alpha_{1}\right\}$ is coefficients of thermal expansion along the $\mathrm{x}$ direction respectively. $\Delta T$ is the $\left(\Delta T=T-T_{0}\right)$ change in temperature in the MWCNTRCB considered as varying distribution over entire length of beam with $T$ is the applied temperature and $T_{0}$ is the atmospheric temperature considered as $300 \mathrm{~K}$ in present analysis.

For the plane stress condition, the stress strain relationship can be represented as, Lal et al. [8]

$$
\left\{\begin{array}{c}
\bar{\sigma}_{X} \\
\bar{\tau}_{x z}
\end{array}\right\}=\left[\begin{array}{cc}
\bar{Q}_{11} & 0 \\
0 & \bar{Q}_{55}
\end{array}\right]\left\{\left\{\bar{\varepsilon}^{L}\right\}+\left\{\bar{\varepsilon}^{N L}\right\}-\left\{\bar{\varepsilon}^{T}\right\}\right\}
$$

Transformed reduce matrix $\bar{Q}_{i j}(i, j=1,5)$ can be represented as,

$$
\begin{aligned}
\bar{Q}_{11} & =Q_{11} \cos ^{4} \theta_{k}+Q_{22} \sin ^{4} \theta_{k} \\
& +2\left(Q_{12}+2 Q_{66}\right) \cos ^{2} \theta_{k} \cos ^{2} \theta_{k} \quad \text { and } \\
\bar{Q}_{55} & =Q_{55} \cos ^{2} \theta_{k}+Q_{44} \sin ^{2} \theta_{k} \quad Q_{11}=\frac{E_{1}}{1-v_{12} v_{21}} ; \\
Q_{22} & =\frac{E_{2}}{1-v_{12} v_{21}} ; \quad Q_{12}=\frac{v_{12} E_{2}}{1-v_{12} v_{21}} ; \quad v_{21}=\frac{v_{12} E_{2}}{E_{1}} ; \\
Q_{55} & =G_{12} ; \quad \text { and } \quad Q_{44}=G_{13}
\end{aligned}
$$

Where $\theta_{k}$ is the fiber orientation.

\subsection{Strain energy of MWCNTRCLB}

The strain energy $\left(\Pi_{1}\right)$ of the MWCNTRCLB for large deformation can be written as,

$$
\Pi_{1}=U_{L}+U_{N L}
$$

The total stain energy $(U)$ consisting of linear $\left(U_{L}\right)$ and nonlinear $\left(U_{N L}\right)$ of the MWCNTRCLB is expressed as, Lal et al. [8]

$$
\begin{aligned}
U & =\left[\int_{A} \frac{1}{2}\left\{\bar{\varepsilon}^{L}\right\}^{T}[D]\left\{\bar{\varepsilon}^{L}\right\} d A\right]_{\text {Linear }} \\
& +\left[\int_{A} \frac{1}{2}\left\{\bar{\varepsilon}^{L}\right\}^{T}\left[D_{1}\right]\left\{\bar{\varepsilon}^{N L}\right\}+\frac{1}{2}\left\{\bar{\varepsilon}^{N L}\right\}^{T}\left[D_{2}\right]\left\{\bar{\varepsilon}^{L}\right\}\right. \\
& \left.+\frac{1}{2}\left\{\bar{\varepsilon}^{N L}\right\}^{T}\left[D_{3}\right]\left\{\bar{\varepsilon}^{N L}\right\} d A\right]_{\text {Non-linear }}
\end{aligned}
$$

Where $\left\{\bar{\varepsilon}^{L}\right\}$ and $\left\{\bar{\varepsilon}^{N L}\right\}$ is linear and nonlinear strain vectors and $D, D_{1}, D_{2}$ and $D_{3}$ are the elastic stiffness matrices for linear and nonlinear case of the MWCNTRCLB, respectively [8].

\section{6 strain energy of foundation system}

The strain energy due to elastic foundation $\left(\Pi_{F}\right)$ considering shear deformable layer with Winkler cubic nonlinearity is written as, Lal et al. [8]

$$
\Pi_{F}=\int_{A} p w d A
$$

The strain energy due to the foundation is rearranged in matrix form and expressed as

$$
\begin{aligned}
\prod_{F} & =\frac{1}{2} \int_{A}\left\{\begin{array}{c}
w \\
w, x
\end{array}\right\}^{T}\left[\begin{array}{cc}
K_{1} & 0 \\
0 & K_{2}
\end{array}\right]\left\{\begin{array}{c}
w \\
w, x
\end{array}\right\} d A \\
& +\frac{1}{2} \int_{A}\left\{\begin{array}{c}
w \\
w, x
\end{array}\right\}^{T}\left[\begin{array}{cc}
K_{3} w^{2} & 0 \\
0 & 0
\end{array}\right]\left\{\begin{array}{c}
w \\
w, x
\end{array}\right\} d A
\end{aligned}
$$

\subsection{Work done due to mechanical and thermal loadings}

Work done due to VIAML $\left(\Pi_{2 M}\right)$ and VIATL $\left(\Pi_{2 T}\right)$ can be written as,

$$
\begin{aligned}
& \Pi_{2 M}=\frac{1}{2} \int_{A} N_{n}^{m x}(u, x)^{2} d A \\
& \Pi_{2 T}=\frac{1}{2} \int_{A} N_{n}^{T x}(u, x)^{2} d A
\end{aligned}
$$

Where, $N_{n}^{m x}=N_{n}^{T x}=N_{0} \times\left[p_{1}\left(x+\frac{a}{2}\right)^{2}+p_{2}\left(x+\frac{a}{2}\right)+p_{3}\right]$ and $\mathrm{N}_{\mathrm{o}}=\int_{0}^{l}\left(1, z, z^{3}\right) Q_{11} \alpha \Delta T d z$

Where $p_{1}, p_{2}$, and $p_{3}$, are input varying factors shown in Figure 2. 


\subsection{Finite element modeling}

Displacement vector and field vector expressed as, Chaudhari et al. [29]

$$
\{q\}=\sum_{i=1}^{N N} N_{i}\{q\}_{i} ; \quad x=\sum_{i=1}^{N N} N_{i} x_{i} ;
$$

Where, $N_{i}=$ interpolation function for the $i$ th node; $\{q\}_{i}=$ the vector of unknown displacements for the $i$ th node; $N N$ $=$ the number of nodes per element; $x_{i}=$ Cartesian coordinate.

The linear interpolation for axial displacement and rotation of normal and Hermite cubic interpolation functions using finite element model Eq. (17), Eq. (12) can be expressed as,

$$
\prod_{1}=\sum_{e=1}^{N E} \prod_{a}^{(e)}=\sum_{e=1}^{N E}\left(U_{L}^{(e)}+U_{N L}^{(e)}\right)
$$

Where, $N E$ and (e) denote the number of elements and elemental, respectively.

Eq. (18) can be further expressed as,

$$
\begin{aligned}
\Pi_{1} & =\frac{1}{2} \sum_{e=1}^{N E}\left[\{q\}^{T(e)}\left[K_{L}+K_{N L}\right]^{(e)}\{q\}^{(e)}\right] \\
& =\{q\}^{T}\left[K_{L}+K_{N L}\right]\{q\} \\
& =\{q\}^{T}\left[K_{L}+\left\{\frac{1}{2}\left[K_{N L_{1}}\right]+\frac{1}{2}\left[K_{N L_{2}}\right]\right\}\right]\{q\}
\end{aligned}
$$

Where, $\left[K_{L}\right],\left[K_{N L 1}\right],\left[K_{N L 2}\right]$, are the global linear, nonlinear stiffness matrices and global displacement vector, respectively.

Using finite element model Eq. (14), Eq. (15) after assembly procedure for foundation analysis can be written as,

$$
\begin{aligned}
\Pi_{F} & =\sum_{e=1}^{N E}\left(\Pi_{F}^{(e)}\right) \\
& =\left\{q^{(e)}\right\}^{T}\left[K_{f L}+K_{f N L}\right]^{(e)}\left\{q^{(e)}\right\} \\
& =\{q\}^{T}\left[K_{f L}+K_{f N L}\right]\{q\}
\end{aligned}
$$

Where, $\left[K_{f L}\right]$ and $\left[K_{f N L}\right]$ is the global linear and nonlinear foundation stiffness matrices, respectively.

Using finite element model Eq. (16) after summing over the entire element work done due to applied loading can be written as,

$$
\begin{aligned}
\Pi_{2} & =\sum_{e=1}^{N E} \Pi_{2}{ }^{(e)}=\frac{1}{2} \sum_{e=1}^{N E}\left\{N_{n}^{m x}\right\}^{T(e)} \lambda\left[K_{g}\right]^{(e)}\left\{N_{n}^{m x}\right\}^{(e)} \\
& =\frac{1}{2} \lambda\{q\}^{T}\left[K_{g}\right]\{q\}
\end{aligned}
$$

Where, $\lambda$ and $\left[K_{g}\right]$ are defined as the thermal or mechanical buckling load parameters and the global geometric stiffness matrix, respectively.

\subsection{Governing buckling equation}

The governing equation for the nonlinear static analysis can be derived using Variational principle, which is generalization of the principle of virtual displacement. For the buckling analysis, the minimization of first variation of total potential energy $\Pi\left(\Pi_{1}+\Pi_{F}-\Pi_{2}\right)$ with respect to displacement vector is given by,

$$
\frac{\partial}{\partial\{q\}}\left(\Pi_{1}+\Pi_{f}-\Pi_{2}\right)=0
$$

By substituting the Eq. (19), Eq. (20), Eq. (21) and Eq. (14) and obtains as

$$
[K]\{q\}=\lambda\left[K_{g}\right]\{q\}
$$

With $[K]=\left\{\left[K_{L}\right]+\left[K_{N L}\right]+\left[K_{f L}\right]+\left[K_{f N L}\right]\right\}$

The stiffness matrix $[K]$ consists of linear and nonlinear beam and foundation stiffness matrices and geometric stiffness matrix $\left[K_{g}\right]$. The parameters $\{q\}$ is the transverse deflection. The solution of Eq. (23) can be obtained using standard solution procedure such as direct iterative, incremental and/ or Newton-Raphson method etc. However, Newton Raphson method is one of the most popular and widely used solution procedure due to fast convergence at higher amplitude.

\subsection{Solution Approach: Direct iterative method}

The system of nonlinear static Eq. (23), can be written as, Chaudhari et al. [29]

$$
[K]\{q\}=\lambda\left[K_{g}\right]\{q\}
$$

1. The nonlinear stiffness matrix is assume as zero and evaluate the nodal buckling parameter by taking linear stiffness matrix only.

2. Normalization of the nodal Eigen vector.

3. For the specified maximum displacement at the end of beam, the displacement vector which is included in $[K]$ matrix, is scaled up by $C$ times so that resultant will have a force $\mathrm{C}$ at the maximum nodal displacement.

4. Using scaled up normalized buckling force, the nonlinear stiffness matrix is obtained. The problem may now again have treated as static equation with new updated stiffness matrix. 
Table 1: Convergence study for laminated composite beam under different boundary conditions

\begin{tabular}{cccccc}
\hline $\mathrm{a} / \mathrm{h}$ & nel & Clamped-clamped (CC) & Clamped-free (CF) & Hinged-hinged (HH) & Clamped- hinged (CH) \\
\hline 5 & 16 & 10.751 & 3.953 & 8.586 & 10.24 \\
& 20 & 10.757 & 3.952 & 8.484 & 10.09 \\
& 24 & 10.677 & 3.951 & 8.421 & 10.00 \\
& 30 & 10.605 & 3.951 & 8.358 & 9.916 \\
& Ref. [23] & 10.970 & 4.721 & 8.585 & 9.492 \\
& Ref. [31] & 11.652 & 4.708 & 8.613 & 9.814 \\
10 & 16 & 31.210 & 5.749 & 19.61 & 24.75 \\
& 20 & 32.003 & 5.746 & 19.23 & 24.63 \\
& 24 & 31.762 & 5.745 & 18.94 & 24.53 \\
& 30 & 31.539 & 5.744 & 18.65 & 25.40 \\
& Ref. [23] & 34.340 & 6.774 & 18.88 & 25.86 \\
& Ref. [31] & 34.453 & 6.772 & 18.83 & \\
\hline
\end{tabular}

5. Steps 2 to 4 are repeated by replacing $\{K\}$ linear to nonlinear $\left\{K_{N L}\right\}$ in steps (1) and (2), to obtained converged buckling parameter with prescribed accuracy of $10^{-3}$.

6. Repeat steps 1 to 5 , for various values of $\mathrm{C}$.

\section{Result and Discussion}

The present study is categorized in three sections. In first section, convergence and validation study is get performed. In second case, the post buckling analysis of MWCNTRCLB under the action of variable inplane axial load is applied, and in third section, post buckling analysis of MWCNTRCLB with variable inplane axial thermal load through length of beam is get performed.

The CLB with two noded with four DOF is used for the present analysis.

The various boundary conditions are used as,

Edges/ends are simply supported (SS): $\mathrm{u}=\mathrm{w}=0$; at $\mathrm{x}$ $=0$, $\mathrm{a}$

Edges/ends are clamped (CC): $\mathrm{u}=\mathrm{w}=\theta \mathrm{x}=\psi \mathrm{x}=0$; at $\mathrm{x}=0$, a

One end is clamped and other is hinged $(\mathrm{CH}): \mathrm{u}=\mathrm{w}=$ $\theta \mathrm{x}=\psi \mathrm{x}=0$; at $\mathrm{x}=0$ and $\mathrm{u}=\mathrm{w}=0$ at $\mathrm{x}=\mathrm{a}$

One end is clamped and other edge is simply supported (CS): $\mathrm{u}=\mathrm{w}=\theta \mathrm{x}=\psi \mathrm{x}=0$; at $\mathrm{x}=0$ and $\mathrm{u}=\mathrm{w}=0$; at $\mathrm{x}=\mathrm{a}$

One end is clamped and other edge is free (CF): $\mathrm{u}=\mathrm{w}$ $=\theta \mathrm{x}=\psi \mathrm{x}=0 ;$ at $\mathrm{x}=0$

\subsection{Convergence and validation study}

The buckling analysis of the laminated composite beam under various boundary conditions is carried out in Table 1 by considering the different number of element (nel). In FEM method proper convergence of the modeling solution is essential so as to get the result near/follow with exact results. The material parameters used for the (0/90/0) composite beam is $E_{1}=40 \times E_{2}, G_{12}=0.6 \times E_{2}, G_{12}=$ $G_{13}, G_{23}=0.5 \times E_{2}, v_{12}=0.25$ and $a / h=5$. Table 1 shows the convergence study for the buckling analysis of laminated composite under boundary condition of CC, CF, $\mathrm{HH}$ and $\mathrm{CH}$ support. Table 1 also presented the validation of dimensionless critical buckling load $\left(\omega \times a^{2}\right) /\left(E_{2} \times b h^{3}\right)$ with the results available in $[23,31]$ and it shows that present results using $\mathrm{C}^{\circ} \mathrm{FEM}$ through HSDT the agreement with available results using FSDT and refined beam theory. The effective convergence results are obtained from initial, so for the convenience 30 number of elements were selected for the further study.

In the Table 2, the accuracy of the present HSDT with FEM model of laminated composite beam is checked by comprising it with the $[23,49,50]$. For the validation purpose $E_{1}=25 \times E_{2}, G_{12}=0.5 \times E_{2}, G_{12}=G_{13}, G_{23}=$ $0.2 \times E_{2}$, and $v_{12}=0.25$ properties are get utilized with different stacking sequence (nL) and varying aspect ratio of the beam. The presented results using $C^{\circ}$ FEM based on HSDT shows the very close agreement with the results presented in the literatures [23] using FSDT, $[49,50]$ using refined/lamination beam theory. One more observation is get concluded from the study is that, when fibers are orientated in a inplane loading direction, it resists more as compared to composites who oriented perpendicular to in- 
Table 2: Validation study for dimensionless buckling load for laminated composite beam for different layups and thickness ratio

\begin{tabular}{|c|c|c|c|c|c|c|c|c|c|c|c|c|c|}
\hline \multirow[t]{2}{*}{$a / h$} & \multirow[t]{2}{*}{$\mathrm{nL}$} & \multicolumn{4}{|c|}{ Hinged-Hinged } & \multicolumn{4}{|c|}{ Clamped-Clamped } & \multicolumn{4}{|c|}{ Clamped-Free } \\
\hline & & Present & Ref. [23] & Ref. [49] & Ref. [50] & Present & Ref. [23] & Ref. [49] & Ref. [50] & Present & Ref. [23] & Ref. [49] & Ref. [50] \\
\hline \multirow[t]{3}{*}{10} & 0 & 14.04 & 13.77 & 13.7 & 13.77 & 28.0 & 27.66 & 27.68 & 27.66 & 3.94 & 4.57 & 4.57 & 4.57 \\
\hline & 90 & 1.03 & 0.807 & 0.78 & 0.784 & 2.50 & 3.050 & 2.755 & 2.747 & 0.171 & 0.204 & 0.203 & 0.203 \\
\hline & $(0 / 90)_{S}$ & 11.3 & 12.31 & 11.2 & 11.18 & 20.8 & 25.24 & 20.82 & 20.80 & 3.364 & 4.047 & 3.922 & 3.922 \\
\hline \multirow[t]{3}{*}{20} & 0 & 20.2 & 18.30 & 18.3 & 18.30 & 54.0 & 55.08 & 55.18 & 55.07 & 4.206 & 4.986 & 4.987 & 4.987 \\
\hline & 90 & 1.06 & 0.818 & 0.81 & 0.812 & 2.83 & 3.227 & 3.145 & 3.135 & 0.171 & 0.205 & 0.205 & 0.205 \\
\hline & $(0 / 90)_{S}$ & 16.5 & 16.19 & 15.7 & 15.69 & 43.5 & 49.26 & 44.81 & 44.72 & 3.675 & 4.393 & 4.362 & 4.362 \\
\hline
\end{tabular}

Table 3: Effect of orientation on critical buckling load under distributed compressive load

\begin{tabular}{cccccccc}
\hline \multirow{2}{*}{$\begin{array}{c}\text { Ply } \\
\text { orientation }\end{array}$} & 5 & 10 & 15 & 20 & 25 & 35 & 50 \\
\hline & 5 & 13.10 & 16.64 & 19.28 & 21.75 & 26.84 & 34.77 \\
$90 / 0 / 0$ & 6.69 & 1.003 & 1.336 & 1.654 & 1.923 & 2.30 & 2.594 \\
$90 / 90$ & 0.683 & 6.98 & 8.75 & 10.147 & 11.504 & 14.34 & 18.66 \\
$0 / 90 / 90$ & 3.75 & 6.98 & 8.75 & 10.147 & 11.504 & 14.34 & 18.66 \\
$90 / 0 / 90$ & 3.75 & 1.763 & 2.32 & 2.87 & 3.37 & 4.12 & 4.75 \\
$0 / 90 / 0$ & 5.71 & 11.81 & 15.27 & 17.72 & 19.91 & 24.32 & 31.26 \\
$45 / 45 / 45$ & 3.089 & 4.85 & 5.98 & 7.108 & 8.276 & 10.617 & 13.624 \\
$45 / 0 / 45$ & 3.44 & 5.36 & 6.63 & 7.88 & 9.19 & 11.79 & 15.09 \\
$0 / 45 / 0$ & 6.1 & 12.41 & 15.87 & 18.39 & 20.71 & 25.44 & 32.86 \\
$15 / 15 / 15$ & 6.215 & 11.848 & 14.94 & 17.31 & 19.576 & 24.28 & 31.536 \\
$15 / 0 / 15$ & 6.28 & 11.94 & 15.05 & 17.44 & 19.73 & 24.48 & 31.803 \\
$0 / 15 / 0$ & 6.63 & 13.00 & 16.53 & 19.152 & 21.59 & 26.64 & 34.49 \\
\hline
\end{tabular}

plane loading direction. So composites are having more longitudinal strength is also get resulted.

In the above analysis the effect of the uniformly distributed load in an inplane direction has been seen. But Figure 3 shows the effect of the inplane load which is axially varied with polynomial distribution on the critical buckling load parameters. The effect over the laminated composite beam under CC boundary condition, $\mathrm{a} / \mathrm{h}=5$, symmetric layups with material properties $E_{1}=25 \times$ $E_{2}, G_{12}=0.5 \times E_{2}, G_{12}=G_{13}, G_{23}=0.2 \times E_{2}, v_{12}=0.25$ presented. Observation clearly shows that with the application of the $N_{5}^{m_{x}}$ loading, maximum value of critical buckling load (CBL) is observed. As compared to inplane UDL, minimum CBL is observed under $N_{2}^{m_{x}}, N_{4}^{m_{x}}, N_{6}^{m_{x}}$ loadings and reverse is true with $N_{3}^{m_{x}}, N_{5}^{m_{x}}$ loadings. Also, as the orientation angle is get increased, the critical buckling load parameter shows the significant effect. Observed results follow the same nature and close agreement with the result presented in [32] using deformable beam theory.

Table 3 elaborate the detailed analysis of the three layered laminated composite beam for the critical buckling analysis under distributed compressive $N_{1}^{m_{x}}$ loading with varying the thickness ratio of beam under CC bound-

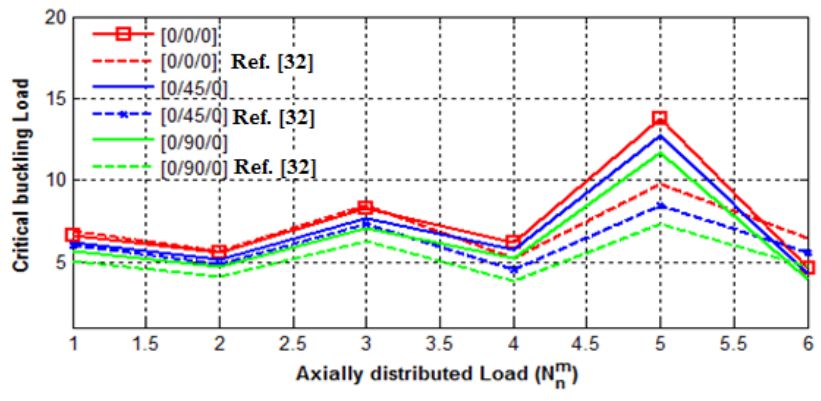

Figure 3: Effect of various axial in-plane loads over the dimensionless critical buckling load for laminated composite beam

ary condition. When only $0^{\circ}$ and $90^{\circ}$ combination is considered, then observation shows that all fibers orientated along longitudinal direction gives maximum value of critical buckling load and lowest critical buckling load is observed when all fibers are oriented in transverse direction to that of applied loading. So precaution should to take that, all fibers are not strictly oriented in $90^{\circ}$ during compressive axial distributed loading otherwise beam will get buckled earlier than required. Study also shows that the other ply orientations like $15^{\circ}, 45^{\circ}, 90^{\circ}$ etc. are utilized 


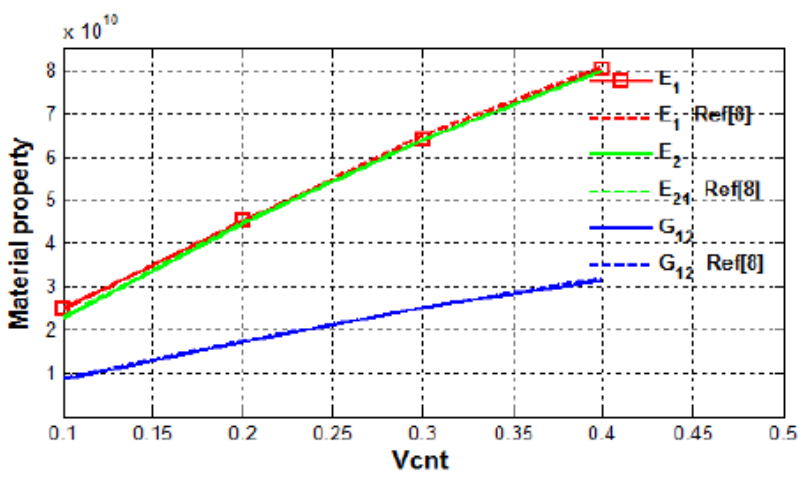

(a)

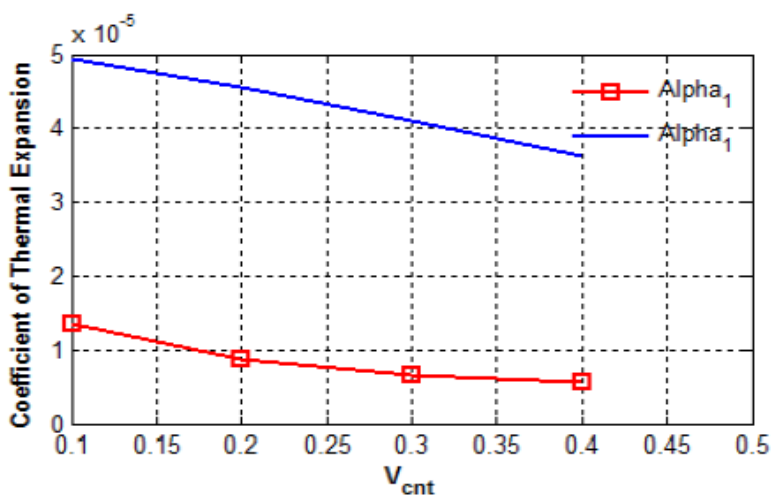

(b)

Figure 4: Effect of variation in SWCNT volume fraction on material property of three phase composite

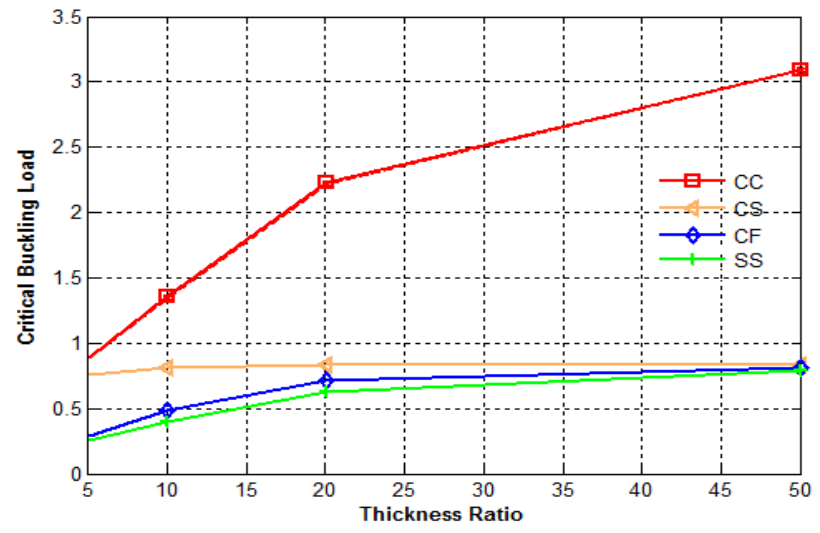

Figure 5: Effect of boundary condition on critical buckling load under $N_{1}^{m_{x}}$

with $0^{\circ}$ and whenever these are placed at second ply position, gives the maximum strength that is maximum value of critical buckling load than any other orientation combination in their respective orientation.

\subsection{Parametric Study under mechanical loading}

Under this study section the three phase material laminated composite beam is get considered. Three phase laminated composite beam is get prepared by two phase matrix which is the combination of matrix and MWCNT and fiber. In this section very first time the effect of SWCNT, MWCNT, the volume fraction of CNT, length to diameter ratio of CNT, ratio of coefficient of thermal expansion, effect of number of walls of CNT, beam aspect ratio with various boundary conditions are get studied to find the critical buckling load with the application of variable inplane loads.
Halpin Tsai model is get utilized for predicting the effective material property of the MWCNTRCs. Poly-methyl methacrylate (PMMA), is selected as a matrix, and its material properties assumed as $E_{m}=2.5 G P a, v_{m}=0.3$, $\rho_{m}=1180 \mathrm{Kg} / \mathrm{m}^{3}$. The arm chair $(10,10)$ SWCNT is reinforced into the matrix to get the new two phase matrix, for that material properties are selected as, $E_{c n t}=1.0 \mathrm{TPa}$, $\rho_{c n t}=1300 \mathrm{Kg} / \mathrm{m}^{3}, v_{c n t}=0.28, L_{c n t} / d_{c n t}=100, h_{\text {in }}=$ $1.5 \times t_{c n t}$ and $\alpha_{11}=5.168 \times 10^{-6}$ also in the present study it is assumed that $\alpha_{11}$ is constant for all layers. The material properties the $E$-glass fiber are taken as in the form of Young's modulus, shear modulus and Poisson ratio as $E_{f}=69 \mathrm{GPa}, G_{f}=28.28 \mathrm{GPa}$ and $v_{f}=0.22$ respectively.

Figure 4(a) shows the variation of elastic material property of three phase composite SWCNTRCs with the variation in the SWCNT volume fraction. It is observed that, as the CNT volume fraction increases in matrix, the overall elastic property of material increases very drastically. The correctness of the present approach is checked by validating it with the [8]. Similarly Figure 4(b) shows the variation in the coefficient of thermal expansion $\alpha_{11}$ and $\alpha_{12}$ which is shown the downward nature with the increasing volume fraction of CNT. The presented result shows very close agreement with the available results from the literature.

Figure 5 shows the linear variation occurred in the critical buckling load with respect to boundary condition and thickness ratio. SWCNT with 0.15 CNT volume fraction is considered for the study. The laminated composite beam $(0 / 90 / 0)$ is experienced the uniformly distributed inplane axially varying load. Particular study focused to observe the effect of boundary conditions. So from the figure it is observed that the SWCNTRC beam under CC support possess the highest critical buckling load whereas with SS support possess the lowest critical buckling load. If compari- 
Table 4: Nonlinear performance of MWCNTRCB with CNT volume fraction

\begin{tabular}{cccccccc}
\hline \multirow{2}{*}{$\mathrm{N}_{w}$} & $\begin{array}{c}\text { Foundation } \\
\text { stiffness }\end{array}$ & $\mathrm{V}_{\text {cnt }}$ & \multicolumn{5}{c}{$\mathrm{W}_{\max }$} \\
\cline { 4 - 7 } & & 0 & 0.1 & 0.2 & 0.3 & 0.4 \\
\hline 1 & $K_{1}=0$, & 0.1 & 2.4556 & 2.4598 & 2.4725 & 2.494 & 2.523 \\
& $K_{2}=0$, & 0.2 & 4.603 & 4.611 & 4.6342 & 4.673 & 4.7274 \\
& $K_{3}=0$ & 0.3 & 6.537 & 6.5488 & 6.5816 & 6.6363 & 6.7131 \\
& $K_{1}=1000$, & 0.1 & 2.4858 & 2.4902 & 2.5030 & 2.524 & 2.5539 \\
& $K_{2}=100$, & 0.2 & 4.6334 & 4.6414 & 4.6648 & 4.7037 & 4.7582 \\
& $K_{3}=100$ & 0.3 & 6.5680 & 6.5791 & 6.6121 & 6.6671 & 6.7440 \\
& $K_{1}=0$, & 0.1 & 1.1658 & 1.1680 & 1.175 & 1.1855 & 1.200 \\
5 & $K_{2}=0$, & 0.2 & 2.1535 & 2.1575 & 2.1693 & 2.1891 & 2.2168 \\
& $K_{3}=0$ & 0.3 & 3.2068 & 3.2125 & 3.2296 & 3.2582 & 3.2982 \\
& $K_{1}=1000$, & 0.1 & 1.1961 & 1.1984 & 1.2051 & 1.2163 & 1.2317 \\
& $K_{2}=100$, & 0.2 & 2.1837 & 2.1879 & 2.1999 & 2.2198 & 2.2477 \\
& $K_{3}=100$ & 0.3 & 3.237 & 3.2429 & 3.2602 & 3.289 & 3.3292 \\
\hline
\end{tabular}

son is performed between the CC and SS boundary condition then critical buckling load under $\mathrm{CC}$ is $70 \%$ more.

The nonlinear buckling behaviour of MWCNTRC beam under SS boundary condition, aspect ratio of 5 with $N_{1}^{m_{x}}$ uniformly distributed inplane polynomial loading for $(0 / 90 / 0)$ presented in Table 4 under the effect of foundation stiffness $K_{1}=1000, K_{2}=100, K_{3}=100$. There are three types of effect has been studied under this study. First, effect of number of walls of CNT. Second, effect of variation of CNT volume fraction, and third, effect of foundation over MWCNTRC beam. With the case of foundation, when observing the CNTRLCB then observation shows that critical buckling load get increased by 1.0 to $1.5 \%, 0.5-1.0 \%$, $0.5 \%$ with the use of mentioned foundation in case of SWCNTRCLB. Similarly in MWCNTRCLB, critical buckling load get increased by 2.5 to $3.0 \%, 1.2$ to $1.5 \%, 1.0 \%$ with the use of foundation parameters. Whenever MWCNT volume fraction is get varied from 0.1 to 0.3 , then it is clearly observed that the beam stiffness is get increased and so resistance offered by it. With the increment in Vcnt from 0.1 to 0.2 , the critical buckling load is get increased by $46 \%$, from 0.2 to 0.3 , the critical buckling load is get increased by $29 \%$ and if comparing Vcnt $=0.1$ to 0.3 , then it is get increased by $62 \%$. With the case of SWCNT and MWCNT use, it shows that SWCNT reinforcing into matrix is more effective than MWCNT because of its structural performance. The buckling resistance offered by the SWCNTRC is quite good over the MWCNTRC. Next observation comes out with the nature of nonlinearity $\left(\mathrm{W}_{\max } / \mathrm{h}\right)$ when varied from 0.1 to 0.4 , then magnitude of critical buckling load is get increased by amount of $2.5 \%$.

Figure 6 shows the effect of Winkler and Pasternak nonlinear foundation model effect over the critical buck-

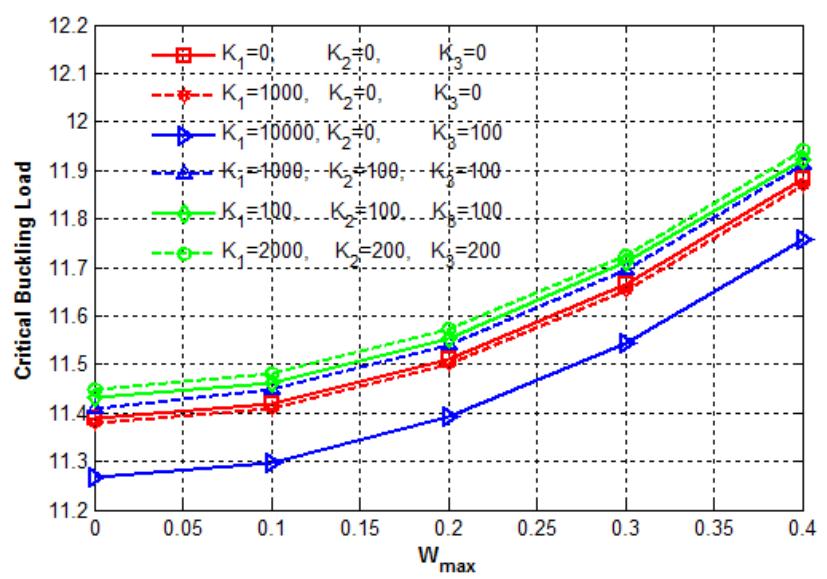

Figure 6: Effect of foundation parameters on critical buckling load

ling load under uniformly distributed inplane load $N_{1}^{m_{x}}$, aspect ratio of 15 , and SS boundary condition with $0.25 \%$ of SWCNT volume fraction on SWCNTRLCB. There are two observations comes out from the study. First, whenever foundation parameter doubled, the foundation supporting nature increases. Secondly, the effect of shear parameter $\mathrm{K}_{2}$. It is observed that as effect of shear foundation increases, the supporting strength of the foundation increases drastically. So Pasternak (shear) foundation stiffness is one of the important parameter in the support/foundation system.

Table 5 gives the total study of effect of CNT utilization and its parameter variation over CBL under different polynomial inplane loading conditions. There are three types of study is get carried out under the chart. First observation gives the effect of SWCNT and MWCNT. Second observation gives the effect of CNT aspect ratio, and third 
Table 5: Effect of MWCNT, its thickness and aspect ratio on CBL analysis

\begin{tabular}{|c|c|c|c|c|c|c|c|c|}
\hline \multirow[t]{2}{*}{$\mathrm{N}_{w}$} & \multirow[t]{2}{*}{$\mathrm{h}_{\text {in }} / \mathrm{t}_{\text {cnt }}$} & \multirow[t]{2}{*}{$\mathrm{l} / \mathrm{d}_{m o}$} & \multicolumn{6}{|c|}{ Inplane polynomial loading } \\
\hline & & & $N_{1}^{m_{x}}$ & $N_{2}^{m_{x}}$ & $N_{3}^{m_{x}}$ & $N_{4}^{m_{x}}$ & $N_{5}^{m_{x}}$ & $N_{6}^{m_{x}}$ \\
\hline \multirow[t]{3}{*}{1} & 0.5 & 20 & 4.419 & 6.198 & 9.239 & 6.904 & 15.341 & 5.146 \\
\hline & & 60 & 11.222 & 9.375 & 13.975 & 10.443 & 23.205 & 7.783 \\
\hline & & 100 & 13.151 & 10.987 & 16.377 & 12.238 & 27.193 & 9.121 \\
\hline \multirow[t]{9}{*}{2} & 0.5 & 20 & 6.979 & 5.831 & 8.692 & 6.495 & 14.432 & 4.841 \\
\hline & & 60 & 11.227 & 9.379 & 13.981 & 10.447 & 23.214 & 7.787 \\
\hline & & 100 & 13.711 & 11.455 & 17.074 & 12.759 & 28.351 & 9.509 \\
\hline & 1.0 & 20 & 6.446 & 5.385 & 8.028 & 5.998 & 13.329 & 4.471 \\
\hline & & 60 & 9.913 & 8.281 & 12.344 & 9.225 & 20.497 & 6.875 \\
\hline & & 100 & 11.833 & 9.886 & 14.736 & 11.012 & 24.468 & 8.207 \\
\hline & 1.5 & 20 & 6.104 & 5.099 & 7.601 & 5.679 & 12.621 & 4.233 \\
\hline & & 60 & 9.060 & 7.569 & 11.283 & 8.431 & 18.735 & 6.284 \\
\hline & & 100 & 10.622 & 8.873 & 13.227 & 9.884 & 21.963 & 7.367 \\
\hline \multirow[t]{9}{*}{3} & 0.5 & 20 & 6.655 & 5.560 & 8.288 & 6.193 & 13.762 & 4.616 \\
\hline & & 60 & 10.876 & 9.086 & 13.544 & 10.121 & 22.489 & 7.543 \\
\hline & & 100 & 13.535 & 11.307 & 16.855 & 12.595 & 27.987 & 9.387 \\
\hline & 1.0 & 20 & 5.546 & 4.634 & 6.907 & 5.161 & 11.469 & 3.847 \\
\hline & & 60 & 8.478 & 7.083 & 10.558 & 7.889 & 17.531 & 5.880 \\
\hline & & 100 & 10.304 & 8.608 & 12.832 & 9.589 & 21.307 & 7.147 \\
\hline & 1.5 & 20 & 5.752 & 4.805 & 7.163 & 5.353 & 11.893 & 3.989 \\
\hline & & 60 & 8.468 & 7.074 & 10.545 & 7.879 & 17.509 & 5.873 \\
\hline & & 100 & 9.939 & 8.304 & 12.378 & 9.249 & 20.553 & 6.894 \\
\hline
\end{tabular}

study gives the effect of variation of $\mathrm{h}_{\text {in }} / \mathrm{t}_{\text {cnt }}$ for SWCNT and MWCNT. For the applied inplane polynomial loading, when CNT aspect ratio increased from 20 to 100, the CBL is get increased by an amount of $65-70 \%$ for $N_{1}^{m_{x}}$ and $45 \%$ for other loadings. Increased in aspect ratio means availability of more surface area for utilization. When ratio of $\mathrm{h}_{\text {in }} / \mathrm{t}_{\text {cnt }}$ increased from 0.5 to 1.5 in case MWCNT, then CBL carrying capacity is get reduced down by an amount of $10-15 \%$. Third observation comes out regarding SWCNT and MWCNT use. With the utilization of SWCNTRCLB, the more buckling resistance is observed than MWCNTRCLB. Along with the stated observation, one more interesting observation noted down from the study. Whenever considering only SWCNT and double walled CNT (DWCNT), with $\mathrm{h}_{\text {in }} / \mathrm{t}_{\text {cnt }} 0.5$ with CNT aspect ratio of 60 and 100 , DWCNTRCLB behaves superior than any other case. With the DWCNT and SWCNT aspect ratio of 60 and 100, 4.04.3\% and 0.04-0.05\% more CBL is observed than SWCNT. General observation shows that, structural point of view SWCNT is comparably more efficient over MWCNT, but this study allows to facilitate the optional case with DWCNT for certain situation. With the further readings, SWCNT found to be dominant over the remaining cases.

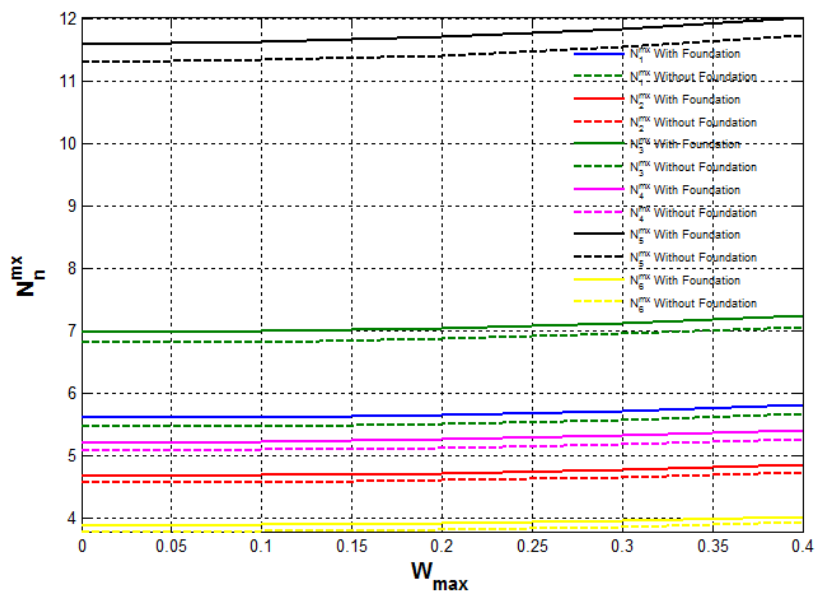

Figure 7: Variation in nonlinear critical buckling load with respect to foundation under varying inplane loading conditions

Figure 7 shows the effect of foundation $\left(K_{1}=10000\right.$, $\left.K_{2}=100, K_{3}=100\right)$ on non-dimensionalised CBL for SWCNTRLCB of (0/90/0), CNT aspect ratio of $100, \mathrm{~h}_{\text {in }} / \mathrm{t}_{\text {cnt }}=1.5$, beam aspect ratio 10 under the CF boundary condition where ' $n$ ' is varying from 1 to 6 . When nonlinearity is varying from 0 to 0.4 , the CBL is increased by $3.7 \%$ for all type of polynomial loads. It is also observed that, with the appli- 
Table 6: Linear and nonlinear non-dimensionalised CBL variation for different SWCNT volume fraction

\begin{tabular}{|c|c|c|c|c|c|c|}
\hline Loading & $\mathrm{W}_{\max }$ & $\mathrm{V}_{c n t}$ & Mode 1 & Mode 2 & Mode 3 & Mode 4 \\
\hline \multirow[t]{8}{*}{$N_{1}^{m_{x}}$} & 0.0 & 0.1 & 17.095 & 39.91 & 75.089 & 116.525 \\
\hline & & 0.2 & 32.357 & 74.808 & 140.857 & 218.729 \\
\hline & & 0.3 & 46.15 & 106.22 & 200.08 & 310.754 \\
\hline & & 0.4 & 57.655 & 132.62 & 249.832 & 388.02 \\
\hline & 0.1 & 0.1 & 21.20 & 47.36 & 81.389 & 122.93 \\
\hline & & 0.2 & 32.38 & 74.858 & 140.897 & 218.769 \\
\hline & & 0.3 & 46.187 & 106.29 & 200.142 & 310.81 \\
\hline & & 0.4 & 72.696 & 159.693 & 272.397 & 410.961 \\
\hline \multirow[t]{8}{*}{$N_{2}^{m_{x}}$} & 0.0 & 0.1 & 14.282 & 33.346 & 62.732 & 97.3488 \\
\hline & & 0.2 & 27.032 & 62.497 & 117.676 & 182.7318 \\
\hline & & 0.3 & 38.555 & 88.7418 & 167.159 & 259.612 \\
\hline & & 0.4 & 48.166 & 110.794 & 208.717 & 324.163 \\
\hline & 0.1 & 0.1 & 18.269 & 41.16 & 69.216 & 103.928 \\
\hline & & 0.2 & 27.056 & 62.538 & 117.71 & 182.766 \\
\hline & & 0.3 & 38.586 & 88.798 & 167.203 & 259.657 \\
\hline & & 0.4 & 63.045 & 140.03 & 232.588 & 348.358 \\
\hline \multirow[t]{8}{*}{$N_{3}^{m_{x}}$} & 0.0 & 0.1 & 21.289 & 49.707 & 93.511 & 145.112 \\
\hline & & 0.2 & 40.295 & 93.16 & 175.413 & 272.388 \\
\hline & & 0.3 & 57.472 & 132.28 & 249.174 & 386.988 \\
\hline & & 0.4 & 71.799 & 165.155 & 311.122 & 483.212 \\
\hline & 0.1 & 0.1 & 21.31 & 49.74 & 93.5367 & 145.139 \\
\hline & & 0.2 & 40.331 & 93.222 & 175.463 & 272.439 \\
\hline & & 0.3 & 57.518 & 132.367 & 249.24 & 387.056 \\
\hline & & 0.4 & 71.856 & 165.261 & 311.205 & 483.297 \\
\hline \multirow[t]{8}{*}{$N_{4}^{m_{x}}$} & 0.0 & 0.1 & 15.9089 & 37.144 & 69.8769 & 108.44 \\
\hline & & 0.2 & 30.11 & 69.52 & 131.08 & 203.545 \\
\hline & & 0.3 & 42.947 & 98.849 & 186.198 & 289.181 \\
\hline & & 0.4 & 53.653 & 123.41 & 232.489 & 361.086 \\
\hline & 0.1 & 0.1 & 19.8176 & 44.314 & 75.9227 & 114.582 \\
\hline & & 0.2 & 30.137 & 69.661 & 131.11 & 203.583 \\
\hline & & 0.3 & 42.981 & 98.913 & 186.248 & 289.232 \\
\hline & & 0.4 & 53.70 & 123.495 & 232.555 & 361.154 \\
\hline
\end{tabular}

cation of foundation parameters, the CBL is get increased by an amount $2.5 \%$. So it is clear that foundation provide more safety to the structure against buckling. Maximum CBL is observed with $N_{5}^{m_{x}}$ and with $N_{6}^{m_{x}}$ minimum CBL is get observed.

There are four inplane polynomial loading conditions are considered for the study of SWCNTRCLB with ply orientation (0/45/0), beam aspect ratio of $15, K_{1}=10000, K_{2}=100$, $K_{3}=100$ under CC boundary condition, to find out the $1^{\text {st }}$, $2^{\text {nd }}, 3^{\text {rd }}$ and $4^{\text {th }} \mathrm{CBL}$. The first general observation found that magnitude of CBL increasing by $80-85 \%$ for linear and nonlinear states from first to last mode in Table 6 . Whenever considering the intermediate cases, then study shows that, from mode 1 to mode 2 - $55 \%$, from mode 2 to mode 3 -
$47 \%$, from mode 3 to mode $4-35 \%$ increment were noted in CBL. Similarly when effect of SWCNT volume fraction studied then it is observed that $45-47 \%$ increment were recorded in CBL for SWCNT volume fraction of 0.2 than 0.1 , also $30 \%$ and $20 \%$ increment observed for CNT volume fraction 0.2 to 0.3 and 0.3 to 0.4 respectively. so study shows that, though increment in SWCNT volume fraction increases the buckling resistance, maximum intermediate drastic increment were found with 0.1 to 0.2 SWCNT volume fraction use.

Table 7 shows the effect of dimensionless CBL with ply orientation scheme of elastically supported laminated composite beam, $\mathrm{V}_{c n t}=0.1,\left(K_{1}=2000, K_{2}=200, K_{3}=100\right)$, aspect ratio of 100 , CF boundary condition for $N_{5}^{m_{x}}$ load- 
Table 7: Effect of lamination scheme on CBL by using two phase and three phase composite material

\begin{tabular}{ccccc}
\hline Ply orientation & $\begin{array}{c}\text { Fiber + Matrix }(2 \\
\text { phase })\end{array}$ & $\begin{array}{c}\text { Matrix + MWCNT } \\
(2 \text { phase })\end{array}$ & $\begin{array}{c}\text { Fiber + Matrix + MWCNT } \\
(\mathrm{Nw}=10)(3 \text { phase })\end{array}$ & $\begin{array}{c}\text { Fiber + Matrix + SWCNT } \\
\text { (3 phase) }\end{array}$ \\
\hline $0 / 90$ & 1.8883 & 2.129 & 5.945 & 15.9601 \\
& $(1.8683)$ & $(2.1075)$ & $(5.8537)$ & $(15.7616)$ \\
$0 / 90 / 0$ & 1.8884 & 2.1489 & 7.409 & 16.5896 \\
& $(1.8683)$ & $(2.1268)$ & $(7.317)$ & $(16.391)$ \\
$0 / 45 / 0$ & 1.8884 & 2.1505 & 7.437 & 16.599 \\
& $(1.8683)$ & $(2.128)$ & $(7.3452)$ & $(16.401)$ \\
$0 / 15 / 15 / 0$ & 1.8885 & 2.1508 & 7.474 & 16.6154 \\
& $(1.8683)$ & $(2.1287)$ & $(7.382)$ & $(16.4167)$ \\
\hline
\end{tabular}

Table 8: Effect of elasticity ratio and CTE on CBT under different support conditions

\begin{tabular}{|c|c|c|c|c|c|c|c|}
\hline \multicolumn{4}{|c|}{ Support : CC } & \multicolumn{4}{|c|}{ Support: SS } \\
\hline \multirow{2}{*}{$\mathrm{E}_{1} / \mathrm{E}_{2}$} & \multirow{2}{*}{$\alpha_{2} / \alpha_{1}$} & \multicolumn{2}{|c|}{ CBT } & \multirow[t]{2}{*}{$E_{1} / E_{2}$} & \multirow[t]{2}{*}{$\alpha_{2} / \alpha_{1}$} & \multicolumn{2}{|c|}{ CBT } \\
\hline & & Ref. [53] & Present & & & Ref. [53] & Present \\
\hline \multirow[t]{2}{*}{20} & 3 & 1.81 & 1.73 & 20 & 3 & 0.791 & 0.731 \\
\hline & 10 & 1.46 & 1.41 & & 10 & 0.64 & 0.592 \\
\hline \multirow[t]{2}{*}{30} & 3 & 1.46 & 1.41 & 30 & 3 & 0.727 & 0.679 \\
\hline & 10 & 1.25 & 1.21 & & 10 & 0.626 & 0.584 \\
\hline \multirow[t]{2}{*}{40} & 3 & 1.22 & 1.20 & 40 & 3 & 0.666 & 0.627 \\
\hline & 10 & 1.09 & 1.05 & & 10 & 0.593 & 0.558 \\
\hline
\end{tabular}

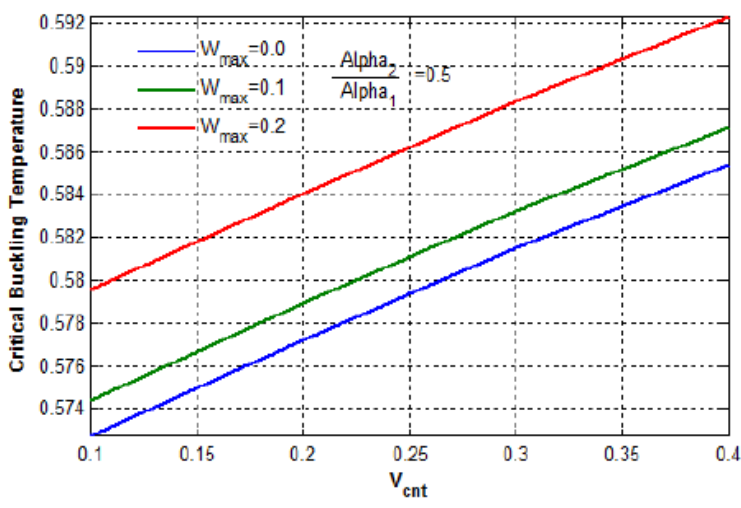

(a)

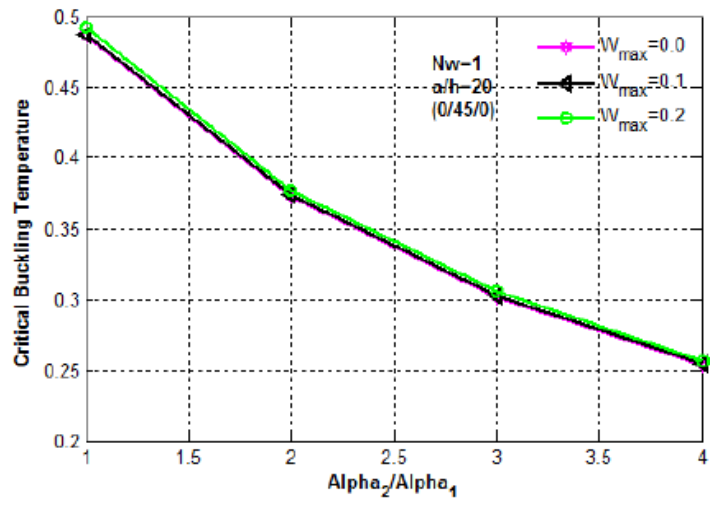

(b)

Figure 8: Influence of (a) SWCNT volume fraction and (b) ratio of CTE on CBT

ing. Under the action of mentioned loading, there is minimum CBL occurs in a conventional two phase composite. If fibers are get replaced by the MWCNT of two phase composites behaves improved results by $11-13 \%$ than previous case. The utilization of UD SWCNT and MWCNT dispersed in conventional matrix then reinforced with E-glass fiber as three phase composites shows the maximum CBL. With the ESMWCNTRCLB around $65-70 \%$ more improvement observed in CBL than two phase composites, whereas this im- provement is quite high with three phase ESSWCNTRCLB. Results clearly reveled that, the importance and advantage of three phase composite material utilization over conventional two phase composite material.

\subsection{Parametric Study under thermal loading}

For the thermal buckling analysis of ESMWCNTRCLB based on higher order shear deformation theory the com- 
Table 9: Variation in CBT with inplane polynomial thermal forces with the CNT volume fraction and CTE

\begin{tabular}{|c|c|c|c|c|c|c|c|c|}
\hline$\frac{\alpha_{2}}{\alpha_{1}}$ & $\mathbf{N}_{w}$ & $\mathrm{~V}_{c n t}$ & $N_{1}^{T_{X}}$ & $N_{2}^{T_{X}}$ & $N_{3}^{T_{x}}$ & $N_{4}^{T_{X}}$ & $N_{5}^{T_{X}}$ & $N_{6}^{T_{X}}$ \\
\hline \multirow[t]{6}{*}{0.2} & 1 & 0.1 & 0.6429 & 0.5362 & 0.8020 & 0.5979 & 1.3353 & 0.4443 \\
\hline & & & $(0.6410)$ & $(0.5346)$ & $(0.7996)$ & $(0.5961)$ & (1.3313) & $(0.4429)$ \\
\hline & & 0.2 & 0.6508 & 0.54317 & 0.8114 & 0.6054 & 1.3495 & 0.4503 \\
\hline & & & $(0.6489)$ & $(0.5415)$ & $(0.8090)$ & $(0.6036)$ & $(1.3456)$ & $(0.4490)$ \\
\hline & & 0.3 & 0.6558 & 0.5475 & 0.8174 & 0.6101 & 1.359 & 0.4540 \\
\hline & & & $(0.6539)$ & $(0.5459)$ & $(0.8150)$ & $(0.6083)$ & (1.3551) & $(0.4527)$ \\
\hline \multirow[t]{6}{*}{0.2} & 3 & 0.1 & 0.6304 & 0.5258 & 0.7864 & 0.5863 & 1.3095 & 0.4356 \\
\hline & & & $(0.6284)$ & $(0.5241)$ & $(0.7839)$ & $(0.5844)$ & (1.3053) & $(0.4242)$ \\
\hline & & 0.2 & 0.6408 & 0.5348 & 0.7989 & 0.5961 & 1.3289 & 0.4434 \\
\hline & & & $(0.6389)$ & $(0.5331)$ & $(0.7965)$ & $(0.5943)$ & (1.3248) & $(0.4420)$ \\
\hline & & 0.3 & 0.6499 & 0.5425 & 0.8100 & 0.6046 & 1.3468 & 0.4499 \\
\hline & & & $(0.6480)$ & $(0.5409)$ & $(0.8076)$ & $(0.6028)$ & (1.3428) & $(0.4486)$ \\
\hline \multirow[t]{6}{*}{0.4} & 1 & 0.1 & 0.5955 & 0.4966 & 0.7430 & 0.5538 & 1.2373 & 0.4114 \\
\hline & & & $(0.5938)$ & $(0.4951)$ & $(0.7408)$ & $(0.5522)$ & (1.2330) & $(0.4101)$ \\
\hline & & 0.2 & 0.6011 & 0.5016 & 0.7494 & 0.5591 & 1.2466 & 0.4158 \\
\hline & & & $(0.5993)$ & $(0.5001)$ & $(0.7472)$ & $(0.5574)$ & $(1.2430)$ & $(0.4146)$ \\
\hline & & 0.3 & 0.6056 & 0.5055 & 0.7548 & 0.5633 & 1.2551 & 0.4192 \\
\hline & & & $(0.6038)$ & $(0.5040)$ & $(0.7526)$ & $(0.5617)$ & (1.2514) & $(0.4179)$ \\
\hline \multirow[t]{6}{*}{0.4} & 3 & 0.1 & 0.5916 & 0.4934 & 0.7381 & 0.5502 & 1.2293 & 0.4087 \\
\hline & & & $(0.5897)$ & $(0.4918)$ & $(0.7358)$ & $(0.5484)$ & $(1.2253)$ & $(0.4073)$ \\
\hline & & 0.2 & 0.5981 & 0.4990 & 0.7456 & 0.5563 & 1.2404 & 0.4137 \\
\hline & & & $(0.5962)$ & $(0.4973)$ & $(0.7433)$ & $(0.5546)$ & $(1.2366)$ & $(0.4124)$ \\
\hline & & 0.3 & 0.6037 & 0.5039 & 0.7524 & 0.5616 & 1.2511 & 0.4178 \\
\hline & & & $(0.6018)$ & $(0.5023)$ & $(0.7502)$ & $(0.5599)$ & $(1.2474)$ & $(0.4166)$ \\
\hline
\end{tabular}

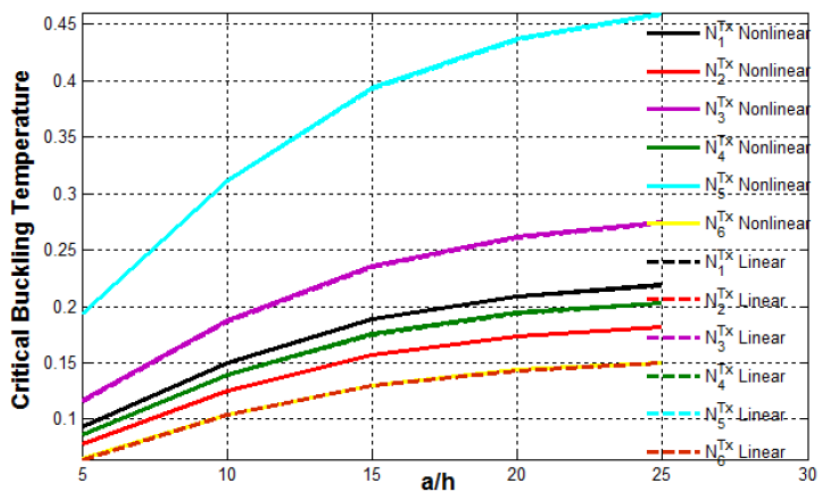

Figure 9: Variation in CBT with ESSWCNTRCLB aspect ratio

puter program is generated so as solve numerous problems. Unless stated the individual ply thickness of laminated composite maintained equal. To check the exactness of the MATLAB code, the results of the critical buckling temperature under different boundary condition, for different elasticity ratio with variation in ratio of coefficient of thermal expansion (CTE) and aspect ratio of 10 are get validated with Ref. [53] as shown in Table 8. For the study (0/90/0) lamination scheme is used with nondimensional critical buckling temperature $\left(T_{c r} a^{2} \alpha_{1}\right) / h^{2}$. The results shows the close agreement with the result available in literature.

As discussed in the section 3.2, in case of thermal load buckling also, three phase composite material is get implemented in this section. Previously few literatures were elaborated the effect of elasticity ratio and ratio of CTE over the critical thermal buckling, but no one were explained the variation of SWCNT volume fraction and ratio of CTE with linear and nonlinear case under the polynomial thermal inplane buckling load. Figure 8(a) elaborate the influence of variation of SWCNT volume fraction in three phase composite with maintaining ratio of CTE under $N_{1}^{T_{x}}$ and CF boundary condition. Study shows that, by analytically thermal buckling resistance can be improved by varying percentage of SWCNT with maintain constant ratio of CTE of material, as shown in Figure 8(a). About 2 to 2.5\% buckling resistance improvement observed with varying SWCNT from 0.1 to 0.4. Figure 8(b) shows that, as ratio of CTE of material get varying from 1 to 4 , critical buckling 


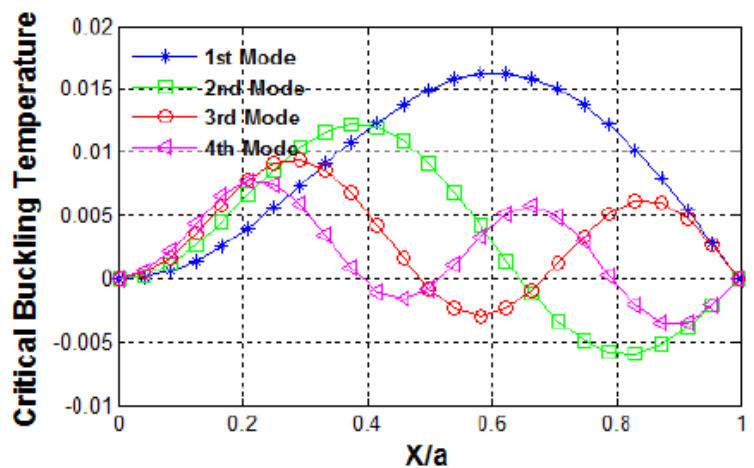

(a)

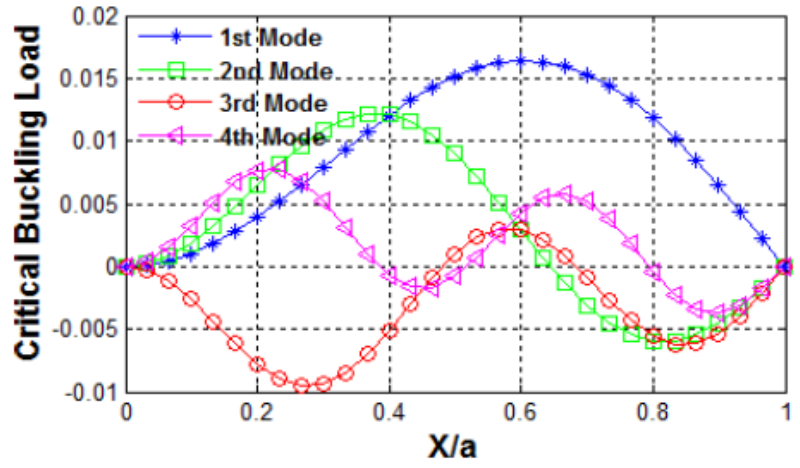

(b)

Figure 10: Buckling mode shape of SWCNTRCLB (a) with VIATL (b) with VIAML

temperature get reduced down by $45 \%$ by maintain volume fraction of SWCNT as 0.1.

Table 9 explains the effect of different inplane compressive thermal forces over the beam buckling with the variation in SW and MWCNT volume fraction, CTE ratio for beam aspect ratio of 20, (0/45/0) ply orientation and CF support condition. Like the mechanical compressive buckling, in inplane thermal compressive buckling also most CBT found with the $N_{6}^{T_{x}}$ while safest regime with $N_{5}^{T_{x}}$ loading. Table 9 clearly stated the idea of effect of different kinds of inplane compressive loads. Observation shows that, about $2 \%$ more critical thermal buckling resistance were obtained with SWCNT utilization than MWCNT as an reinforcement while maintaining constant ratio of CTE. With increasing the ratio of CTE of material, the thermal buckling resistance is get lowered down. So selection of parameters are in such a way that where the required strength against buckling will get achieved.

Figure 9 shows the effect of various inplane thermal loadings under CF support with respect to SWCNTRCLB $(0 / 90 / 0)$ of aspect ratio 15 , SWCNT volume fraction 0.15 and foundation parameter of $\left(K_{1}=100, K_{2}=100, K_{3}=100\right)$ over non-dimensional critical buckling temperature. Results shows that, as aspect ratio increases, the critical buckling thermal resistance of the beam also increases. About a 55-56\% difference in non-dimensionalised CBT between thick $(\mathrm{a} / \mathrm{h}=5)$ and thin $(\mathrm{a} / \mathrm{h}=25)$ composite beam.

Figure 10 shows the thermal post buckling mode shapes of SWCNTRCLB under uniformly distributed load, HH boundary condition, SWCNT volume fraction of 0.15 , ply orientation (0/90/0), $\mathrm{W}_{\max }=0$ and aspect ratio of 20 . First, second, third and fourth mode of buckling are shown in the figure. First mode started the critical buckling and shows that under first mode beam is more critical. The graph shows the instability in the beam raised with the first critical buckling mode. So buckling mode shows the severity in the critical buckling situation.

\section{Conclusion}

Here, thermal and mechanical load induced non-linear analysis of multi walled carbon nanotube reinforced composite laminated beam (MWCNTRCLB) under elastic foundation using higher order shear deformation theory and von Karman kinematics is carried out. The study shows the uniqueness in itself, because, first time three phase composite material is get utilized along with varying inplane mechanical and thermal loading under the elastic foundation and different boundary conditions. Following are some of the important observations comes out from the performed limited study,

- With the ESMWCNTRCLB around 65-70\% more improvement observed in CBL than two phase composites, whereas this improvement is quite high with three phase ESSWCNTRCLB. Results clearly reveled that, the importance and advantage of three phase composite material utilization over conventional two phase composite material.

- When fibers are orientated in a inplane loading direction, it resists more as compared to composites who oriented perpendicular to inplane loading direction. So composites are having more longitudinal strength is also get resulted.

- Observation clearly shows that with the application of the inplane axially varied $N_{5}^{m_{x}}$ loading, maximum value of critical buckling load (CBL) is observed. As compared to inplane UDL, minimum CBL is observed under $N_{2}^{m_{x}}, N_{4}^{m_{x}}, N_{6}^{m_{x}}$ loadings and reverse is true with $N_{3}^{m_{x}}, N_{5}^{m_{x}}$ loadings. Also, as the orientation 
angle is get increased, the critical buckling load parameter shows the significant effect.

- it is observed that the SWCNTRC beam under CC support possess the highest critical buckling load whereas with SS support possess the lowest critical buckling load

- With the case of foundation, when observing the CNTRCLB then observation shows that critical buckling load get increased by 1.0 to $1.5 \%, 0.5-1.0 \%, 0.5 \%$ in case of SWCNTRCLB. Similarly in MWCNTRCLB, critical buckling load get increased by 2.5 to $3.0 \%, 1.2$ to $1.5 \%, 1.0 \%$ with the use of foundation parameters. Also with SWCNT and MWCNT use, it shows that SWCNT reinforcing into matrix is more effective than MWCNT because of its structural performance.

- It is observed that, as effect of shear foundation increases, the supporting strength of the foundation increases drastically. So Pasternak (shear) foundation stiffness is one of the important parameter in the support/foundation system.

- With the DWCNT and SWCNT aspect ratio of 60 and $100,4.0-4.3 \%$ and $0.04-0.05 \%$ more CBL is observed than SWCNT. General observation shows that, structural point of view SWCNT is comparably more efficient over MWCNT, but this study allows to facilitate the optional case with DWCNT for certain situation. With the further readings, SWCNT found to be dominant over the remaining cases

- About $2 \%$ more critical thermal buckling resistance were obtained with SWCNT utilization than MWCNT as a reinforcement while maintaining constant ratio of CTE. With increasing the ratio of CTE of material, the thermal buckling resistance is get lowered down. Also, as aspect ratio increases, the critical buckling thermal resistance of the beam also increases. About a 55-56\% difference in non-dimensionalised CBT between thick $(\mathrm{a} / \mathrm{h}=5)$ and thin $(\mathrm{a} / \mathrm{h}=25)$ composite beam.

\section{References}

[1] Sui, Q., Lai, C., Fan, H. (2018). Buckling failure modes of onedimensional lattice truss composite structures. Proc IMechE Part G: J Aerospace Engineering, 232(13), 2565-2583.

[2] Stevens, K.A., Ricci, R., Davies, G.A.O. (1995). Buckling and Postbuckling of composite structures. Composites, 26, 189199.

[3] Buskell, N., Davies, G.A.O., Stevens, K.A. (1985). Postbuckling Failure of Composite Panels. Composite Structures, 3, 290-314.

[4] Chavan, S., Lal, A. (2017). Bending analysis of laminated SWCNT Reinforced functionally graded plate Using FEM. Curved and Layer Struct, 4, 134-145.
[5] Huang, B., Guo, Y., Wang, J., Du, J., Qian, Z., Ma, T., Yi, L. (2017). Bending and free vibration analyses of antisymmetrically laminated carbon nanotube-reinforced functionally graded plates. Journal of Composite Materials, 51(22), 3111-3125.

[6] Vo-Duy, T., Ho-Huu, V., Nguyen-Thoi, T. (2017). Free vibration analysis of laminated FG-CNT reinforced composite beams using finite element method. Front. Struct. Civ. Eng. https://doi.org/10.1007/s11709-018-0466-6.

[7] Gunay, E. (2017). Finite element analysis of stress transfer mechanism from matrix to the fiber in SWCN reinforced nanocomposite. AIP Conference Proceedings, 1809, 020021. https://doi.org/10.1063/1.4975436.

[8] Lal, A., Markad, K. (2018). Deflection and stress behaviour of multi-walled carbon nanotube reinforced laminated composite beams. Computers and Concrete 2018; 22(6): 000-000.

[9] Arani, A.G., Zamani, M.H. (2018). Bending analysis of agglomerated carbon nanotube-reinforced beam resting on two parameters modified Vlasov model foundation. Indian J Phys, 92(6), 767-777.

[10] Thakur, A. K., Kumar, P., Srinivas, J. (2016). Studies on Effective Elastic Properties of CNT/Nano-Clay Reinforced Polymer Hybrid Composite. IOP Conference Series: Materials Science and Engineering, 115, 012007. doi:10.1088/1757-899x/115/1/012007

[11] Yip, M.C., Lin, Y.C., Wu, C.L. (2011). Effect of Multi-Walled Carbon Nanotubes Addition on Mechanical Properties of Polymer Composites Laminate. Polymers \& Polymer Composites, 19(2), 131-140.

[12] Islam, M.E., Mahdi, T.H., Hosur, M.V., Jeelani, S. (2015). Characterization of Carbon Fiber Reinforced Epoxy Composites Modified with Nanoclay and Carbon Nanotubes. Procedia Engineering, 105, $821-828$.

[13] Zaeria, M.M., Ziaei-Rada, S., Shahidia, A.R. On the Elastic Constants of Single Walled Carbon Nanotubes. Procedia Materials Science, 11, $666-671$.

[14] Cantournet, S., Boyce, M.C., Tsou, A.H. (2007). Micromechanics and macromechanics of carbon nanotube-enhanced elastomers. Journal of the Mechanics and Physics of Solids, Elsevier, 55 (6), 1321-1339.

[15] Bipin, P.B., Senthikumar, K., Deepak, K.P. (2016). Buckling Analysis of Laminated Carbon Fiber Composite Beam using Ansys. IJERT, 5(7), 399-404.

[16] Kumar, P., Srinivas, J. (2017). Free vibration, bending and buckling of a FG-CNT reinforced composite beam: Comparative analysis with hybrid laminated composite beam. Multidiscipline Modeling in Materials and Structures, 13(4), 590-611.

[17] Kumar, P., Srinivas, J. (2017). Vibration, buckling and bending behaviour of FG-MWCNT reinforced polymer composite plates using the layer-wise formulation. Composite structures, 177, 158170.

[18] Thomas, B., Suresh, T.P. (2017). Vibration and buckling analysis of functionally graded carbon nanotube reinforced composite beams. International Journal of Civil Engineering and Technology, 8(8), 74-84.

[19] Fan, Y., Wang, H. (2015). Nonlinear vibration of matrix cracked laminated beams containing carbon nanotube reinforced composite layers in thermal environments. Composite Structures, 124, 35-43.

[20] Yas, M.H., Samadi, N. (2012). Free vibrations and buckling analysis of carbon nanotube-reinforced composite Timoshenko beams on elastic foundation. International Journal of Pressure Vessels 
and Piping, 98, 119-128.

[21] Vodenitcharova, T., Zhang, L.C. (2006). Bending and local buckling of a nanocomposite beam reinforced by a single-walled carbon nanotube. International Journal of Solids and Structures, 43, 3006-3024.

[22] Madhu, S., Rao, V.V.S., Kumar, P. P. (2013). Buckling Analysis of Carbon Nanotube Reinforced Polymer Composite Plates. IJRMET, 3(2), 51-54.

[23] Kahya, V. (2016). Buckling analysis of laminated composite and sandwich beams by the finite element method. Composites part B, 91, 126-134.

[24] Atlihan, G. (2013). Buckling analysis of delaminated composite beams. Indian journal of Engineering \& Material sci, 20: 276-282.

[25] Kim, H.J., Hong, C.S. (1997). Buckling and post buckling behavior of Composite laminates with a delamination. Compo.sitrs Scirnce and Technology, 57, 557-564.

[26] Lim, Y.B., Parsons, I.D. (1993). The linearized buckling analysis of a Composite beam with multiple delaminations. Int. J. Solids Structures, 30(22), 3085-3099.

[27] Narendar, S. (2011). Buckling analysis of micro-nano-scale plates based on two variable refined plate theory incorporating nonlocal scale effects. Compos Struct, 93, 3093-103.

[28] Pradhan, S.C. (2009). Buckling of single layer graphene sheet based on nonlocal elasticity and higher order shear deformation theory. Phys Lett A, 373, 4182-8.

[29] Chaudhari, V.K., Shegokar, N.L., Lal, A. (2017). Stochastic thermomechanically induced post buckling response of elastically supported nanotube-reinforced composite beam. Advances in Aircraft and Spacecraft Science, 4(5), 585-611.

[30] Rafiee, M.A., Rafiee, J., Yu, Z.Z., Koratkar, N. (2009). Buckling resistant graphene nanocomposite. Applied physics letters, 95, 223103.

[31] Khdeir, A.A., Reddy, J.N. (1997). Buckling of cross-ply laminated beam with arbitrary boundary conditions. Composite structures, 37(1), 1-3.

[32] Karamanli, A., Aydogdu, M. (2019). Buckling of laminated composite and sandwich beams due to axially varying in-plane loads. Composite structures, 210, 391-408.

[33] Bouazza, M., Benseddiq, N., Zenkour, A.M. (2019). Thermal buckling analysis of laminated composite beams using hyperbolic refined shear deformation theory. Journal of Thermal Stresses, 42(3), 332-340.

[34] Aydogdu, M. (2007). Thermal buckling analysis of cross-ply laminated composite beams with general boundary conditions. Composite sci. tech., 67, 1096-1104.

[35] Shen, H.S., Xiang, Y. (2013). Nonlinear analysis of nanotubereinforced composite beams resting on elastic foundations in thermal environments. Engineering Structures, 56, 698-708.

[36] Yaghoobi, H., Valipour, M.S., Fereidoon, A., Khoshnevisrad, P. (2014). Analytical study on post-buckling and nonlinear free vibration analysis of FG beams resting on nonlinear elastic foundation under thermo-mechanical loadings using VIM. Steel Composite Struct., 17, 753-776.
[37] Li, S., Batra, R.C. (2007). Thermal buckling and post buckling of Euler-Bernoulli beams supported on nonlinear elastic foundations. AIAAJ, 45, 712.

[38] Li, Z.M., Qiao, P. (2015). Thermal post buckling analysis of anisotropic laminated beams with different boundary conditions resting on two-parameter elastic foundations. Eur. J.Mech A/Solids, 54, 30-43.

[39] Li, S., Song, X. (2006). Large thermal deflections of Timoshenko beams under transversely non-uniform temperature rise. J. Mech. Res. Commun, 33, 84-92.

[40] Pesic, I., Lanc, D., Turkalj, G. (2015). Non-linear thermal buckling analysis of thin walled beam structures. Engineering review, 35(3), 239-245.

[41] Yazdani, S., Kiani, Y., Jabbari, M., Eslami, M.R. (2011). Thermal Buckling of Piezoelectric Composite Beam. ISRN Mechanical Engineering, Article ID 362030, 11 pages. doi:10.5402/2011/362030.

[42] Liu, L., Kardomateas, G.A., Birman, V., Holmes, J.W., Simitses, G.J. (2006). Thermal buckling of a heat-exposed, axially restrained composite column. Compos. Part A Appl. Sci. Manuf., 37, 972980.

[43] Lee, J.J., Choi, S. (1999). Thermal buckling and post buckling analysis of a laminated composite beam with embedded SMA actuators. Compos. Struct., 47, 695-703.

[44] Fu, Y., Wang, J., Hu, S. (2014). Analytical solutions of thermal buckling and post buckling of symmetric laminated composite beams with various boundary conditions. Acta Mech, 225, 13-29.

[45] Akbas, S.D. (2018). Nonlinear thermal displacements of laminated composite beams. Coupled Systems Mechanics, 7(6), 691705.

[46] Kocatürk, T. Akbaş, Ş.D. (2012). Post-buckling analysis of Timoshenko beams made of functionally graded material under thermal loading. Struct. Eng. Mech., 41(6), 775-789.

[47] Kocatürk, T. Akbaş, Ş.D. (2013). Thermal post-buckling analysis of functionally graded beams with temperature dependent physical properties. Steel Compos. Struct, 15(5), 481-505.

[48] Hu, H., Badir, A., Abatan, A. (2003). Buckling behaviour of a graphite/epoxy composite plate under parabolic variation of axial loads. Int J Mech Sci, 45(6-7), 1135-47.

[49] Kapuria, S., Dumir, P.C., Jain, N.K. (2004). Assessment of zigzag theory for static loading, buckling, free and forced vibration of composite and sandwich beams. Composite structures, 64; 317327.

[50] Reddy, J.N. (1997). Mechanics of laminated composite plates: theory and analysis. Boca Raton: CRC press.

[51] Reddy, J.N. (2004). An Introduction to Nonlinear Finite Element Analysis", Oxford University Press, Oxford, USA.

[52] Bhardwaj, G., Upadhyay, A.K., Pandey, R. and Shukla, K.K. (2013). Non-linear flexural and dynamic response of CNT reinforced laminated composite plates. Compos. Part B, 45, 89-100.

[53] Vosoughi, A.R., Malekzadeh, P., Banan, MaR., Banan, MoR. (2012). Thermal buckling and post buckling of laminated composite beams with temperature-dependent properties. International Journal of Non-Linear Mechanics, 47, 96-102. 